CLINICAL STUDY

\title{
Association of serum IGF1 with endothelial function: results from the population-based study of health in Pomerania
}

\author{
Klaus Empen ${ }^{1, *}$, Roberto Lorbeer ${ }^{2, *}$, Henry Völzke ${ }^{2}$, Daniel M Robinson ${ }^{1}$, Nele Friedrich ${ }^{3}$, Alexander Krebs ${ }^{3}$, \\ Matthias Nauck ${ }^{3}$, Thorsten Reffelmann ${ }^{1}$, Ralf Ewert ${ }^{1}$, Stephan B Felix ${ }^{1}$, Henri Wallaschofski ${ }^{3, *}$ and Marcus Dörr ${ }^{1, *}$ \\ ${ }^{1}$ Department of Cardiology, ${ }^{2}$ Institute for Community Medicine and ${ }^{3}$ Institute for Clinical Chemistry and Laboratory Medicine, Ernst Moritz Arndt \\ University of Greifswald, D-17475 Greifswald, Germany
}

(Correspondence should be addressed to K Empen; Email: empen@uni-greifswald.de)

*(K Empen, R Lorbeer, H Wallaschofski and M Dörr contributed equally to this work)

\begin{abstract}
Objective: IGF1 mediates multiple physiological and pathophysiological responses in the cardiovascular system. The aim of this study was to analyze the association between serum IGF1 as well as IGF-binding protein 3 (IGFBP3) levels and endothelial function measured by flow-mediated dilation (FMD).

Design: Cross-sectional population-based observational study.

Methods: The study population comprised 1482 subjects ( 736 women) aged 25-85 years from the Study of Health in Pomerania. Serum IGF1 and IGFBP3 levels were determined by chemiluminescence immunoassays. FMD measurements were performed using standardized ultrasound techniques. FMD values below the sex-specific median were considered low.

Results: In males, logistic regression analyses revealed an odds ratio (OR) of 1.27 (95\% confidence interval (CI) 1.07-1.51; $P=0.008$ ) for decreased FMD for each decrement of IGF1 s.D. after adjustment for major cardiovascular confounders. In females, no significant relationship between serum IGF1 and FMD was found (OR 0.88, CI 0.74-1.05; $P=0.147)$. After exclusion of subjects with the current use of antihypertensive medication, these findings were similar (males: OR 1.40, CI 1.12-1.75; $P=0.003$; females: OR 0.95, CI 0.77-1.16; $P=0.595$ ). There was no association between serum IGFBP3 levels and FMD in both sexes.

Conclusions: Low serum IGF1 levels are associated with impaired endothelial function in males. In women, serum IGF1 is not associated with endothelial function.
\end{abstract}

European Journal of Endocrinology 163 617-623

\section{Introduction}

Insulin-like growth factor-1 (IGF1), a circulating peptide hormone, is structurally and functionally related to insulin (1). IGF1 represents an essential growth factor for the regulation of cell proliferation and differentiation (2). IGF1 is synthesized under the control of GH mainly in hepatic cells (3). However, many other cell types, including cardiac myocytes (4), also secrete IGF1 and are sensitive to its tropic action. IGF1 significantly interacts with endothelial physiology. Human endothelial cells express more IGF1 receptors than insulin receptors (5), and IGF1 stimulates nitric oxide production by endothelial cells, contributing to the regulation of vascular tone and other anti-atherosclerotic properties $(6,7)$. Circulating IGF1 is predominantly bound to IGF-binding proteins (IGFBP). Most of IGF1 is carried by IGFBP3 (8). Consequently, the IGF1/IGFBP3 ratio might mirror the biological impact of total IGF1 levels.

Impaired flow-mediated dilation (FMD) represents endothelial dysfunction and precedes the development of clinically apparent atherosclerosis in humans with cardiovascular risk factors, such as diabetes mellitus, arterial hypertension, hypercholesterolemia, or smoking (9). Circulating IGF1 levels are inversely related to ultrasound measures of atherosclerosis (10), the risk of ischemic heart disease (11), stroke $(12,13)$, coronary events (13), and cardiovascular mortality (14).

Studies designed to elucidate the relationship between serum IGF1 levels and FMD are scarce and primarily confined to patients with disorders in $\mathrm{GH}$ metabolism. In patients with low serum IGF1 levels due to $\mathrm{GH}$ deficiency, substitution of GH leads to normalization of a previously reduced FMD $(15,16)$. On the other hand, in acromegaly patients with high IGF1 levels, surgical resection of the GH-producing tumor was followed by an improvement of previously reduced FMD (17). More recently, an association between serum IGF1 levels and the acetylcholine-stimulated increase of forearm blood flow, as measured by plethysmography, was described in a population of 100 untreated hypertensive patients (18). 
There are no epidemiological data available investigating the potential association of IGF 1 or IGFBP 3 levels with endothelial function. The objective of this study was to analyze the association of serum IGF1 and IGFBP3 levels with endothelial function as measured by FMD in an adult population of a large-scale, crosssectional, population-based study - the Study of Health in Pomerania (SHIP).

\section{Methods}

\section{Study population}

The design of SHIP has been published previously $(19,20)$. Briefly, SHIP is a population-based study in the northeast area of Germany. Baseline examinations were performed in 4308 subjects between 1997 and 2001. The first follow-up examination (SHIP-1) was conducted 5 years (mean $5.2 \pm 0.5$ years) after baseline and comprised 3300 subjects $(83.5 \%$ of the still eligible population). The study was approved by the ethics committee of the University of Greifswald. All participants gave informed written consent.

Between March 2003 and October 2006, 1788 subjects $(54 \%)$ of the SHIP-1 population volunteered for measuring FMD of the brachial artery. Exclusion criteria for FMD measurements were equipment malfunction $(n=36)$, any medical contraindication $(n=19)$, and primarily hypotension with systolic blood pressure (BP) below $100 \mathrm{mmHg}(n=15)$. Image quality of 215 FMD examinations was insufficient for correct readings. In 36 subjects, serum IGF1 levels were not available. This resulted in a final study population of 1482 persons (736 women) with both complete examinations of FMD of at least sufficient image quality and available IGF1 and IGFBP3 datasets. All data and analyses in this report refer to the SHIP-1 population. There was no subject suffering from acromegaly or GH deficiency.

\section{Measurements}

Sociodemographic characteristics and medical histories were assessed by computer-assisted personal interviews. As for smoking status, participants were classified as never-smokers, ex-smokers, or current smokers. The definition of diabetes mellitus was based on self-reported physician's diagnosis or use of antidiabetic medication. Liver disease was defined as self-reported physician's diagnosis. The definition of renal disease was based on self-report or creatinine clearance values $<50 \mathrm{ml} / \mathrm{min}$ as estimated by the Cockcroft-Gault formula (21).

Waist circumference (WC) was measured to the nearest $0.1 \mathrm{~cm}$ using an inelastic tape midway between the lower rib margin and the iliac crest in the horizontal plane, with the subject standing comfortably with weight distributed evenly on both feet. Body mass index (BMI) was calculated as weight in kilograms divided by the square of height in meters. After a $5 \mathrm{~min}$ rest period, systolic and diastolic BP were measured three times at the right arm of seated subjects using a digital BP monitor (HEM-705CP, Omron Corporation, Tokyo, Japan) with each reading being followed by a further rest period of $3 \mathrm{~min}$. The mean of the second and third measurements was calculated and used for the present analyses. Hypertension was defined as a systolic BP of $\geq 140 \mathrm{mmHg}$, a diastolic BP of $\geq 90 \mathrm{mmHg}$, or use of antihypertensive medication.

Nonfasting blood samples were drawn from the cubital vein in the supine position. The samples were taken between 0700 and $1600 \mathrm{~h}$ and analyzed immediately for all parameters except IGF1 and IGFBP3, for which the serum was stored at $-80{ }^{\circ} \mathrm{C}$. Internal quality controls were performed at least daily. Serum creatinine levels were measured with a modified Jaffé method, and total serum cholesterol was measured photometrically (both Dimension RxL HM Max, Siemens Healthcare Diagnostics, Bad Nauheim, Germany). Low- and high-density lipoprotein cholesterol (LDL- and HDL-cholesterol) levels were quantified by lipid electrophoresis (HELENA SAS-3 system, HELENA 7 BioSciences Europe, Tyne \& Wear, UK). Triglycerides and glucose were determined enzymatically using reagents from Roche Diagnostics (Hitachi 717, Roche Diagnostics, Mannheim, Germany). Serum IGF1 and IGFBP3 levels were measured using a chemiluminescent immunometric assay on an Immulite 2500 analyzer (Siemens Immulite 2500; Siemens Healthcare Medical Diagnostics). The assays were performed according to the manufacturer's recommendations by skilled technical personnel. Measurements were carried out from April to May 2008. An aliquot of two levels of the manufacturer's control material (IGF-Control-Module, ref. LGCOC, lot 022, Siemens Healthcare Medical Diagnostics) was included within each series in single determination as reported previously (22). During the course of the study, the inter-assay coefficient of variation was $7.9 \%$ with a systematic deviation of $+2.5 \%$ at the $64 \mathrm{ng} / \mathrm{ml}$ level for the IGF1 assay, and $4.6 \%$ with a systematic deviation of $-2.7 \%$ at the $880 \mathrm{ng} / \mathrm{ml}$ level for the IGFBP3 assay.

\section{Flow-mediated dilation}

FMD was assessed as described previously (23). In brief, FMD of the brachial artery was assessed by measuring the increase in the brachial artery diameter during reactive hyperemia after transient forearm ischemia. The brachial artery was visualized using a $10 \mathrm{MHz}$ linear array transducer (Cypress, Siemens, Erlangen, Germany). Ultrasonography was performed in a dark and quiet room. The participants lay quietly for $1 \mathrm{~min}$ before measurements. A BP cuff was placed around the right forearm $5 \mathrm{~cm}$ distally from the right antecubital crease. B-mode longitudinal images of the brachial 
artery were obtained at the level of the antecubital fossa. After marking the optimal position of the transducer, baseline images of the brachial artery were digitally stored. Arterial flow to the forearm was interrupted by insufflation of the forearm cuff for $5 \mathrm{~min}$ by 200 or $50 \mathrm{mmHg}$ above systolic BP, whichever was highest. Exactly 1 min after cuff deflation, B-mode longitudinal images of the brachial artery were obtained for FMD measurements. Examinations were performed and read by two observers. All ultrasound measurements in SHIP are performed offline and underlie strict quality management (19). Intrareader, intra-observer, interreader, and interobserver variability are evaluated in certification procedures. Before data collection, 25 images were measured twice by each participating reader, and 12 volunteers were examined twice by each participating observer. During data collection, observer certification procedures were repeated semiannually for at least six volunteers. An interval of at least $24 \mathrm{~h}$ was required between examination and reading procedures. The number of images and volunteers was arbitrarily defined before the beginning of the study, and has been proven satisfactory from experience to demonstrate relevant reader and observer differences. All measurements of intrareader, intraobserver, interreader, and interobserver agreements with respect to FMD revealed a mean bias of $<5 \%$ and +2 s.D. of bias of $<25 \%$. The applied quality measures have been described elsewhere in detail (23). End-diastolic vessel diameters were measured from the anterior to the posterior M-line (i.e. the interface between the media and adventitia) of the vessel wall. Diameters were calculated from the average of three measurements of four consecutive cardiac cycles. Absolute FMD was calculated by subtracting baseline vessel diameters from postischemia vessel diameters. Relative changes were expressed as percentage of absolute FMD to baseline diameters. Values below the median of sex-specific distribution were considered decreased.

\section{Statistical analysis}

Data on quantitative characteristics are expressed as mean and S.D. Data on qualitative characteristics are expressed as absolute numbers and percent values. All analyses were done in male and female subjects separately. Comparisons between groups were made using Mann-Whitney's $U$ test (continuous data) and $\chi^{2}$-test (nominal data). Bivariate correlations between variables were determined by Pearson's correlation coefficient $(r)$. Multivariable statistical analyses were performed using logistic regression analysis. Adjusted odds ratios (OR) and 95\% confidence intervals (CI) are provided. Models were developed by adjusting for age, WC, diabetes mellitus, hypertension, liver and renal diseases, smoking status, and serum HDL- and LDL-cholesterol levels. To check for possible selection bias introduced by exclusion of subjects (i.e. nonparticipants of FMD examination), we applied inverse probability weighting according to major variables of difference between the study population and nonparticipants in further sensitivity analyses (24). A value of $P<0.05$ was considered statistically significant. All statistical analyses were performed using Stata 10 (Stata Corporation, College Station, TX, USA).

\section{Results}

Females had smaller baseline diameters of the brachial artery and higher FMD values than males (Table 1). Male subjects were more often current and ex-smokers, had larger WC and BMI, lower HDL-cholesterol values, higher triglyceride and glucose levels, and higher systolic and diastolic BP, and were more often hypertensive than women. No differences regarding the prevalence of diabetes mellitus, liver, and renal diseases became apparent between men and women. Mean serum IGF1 levels did not differ between men and women, whereas men had lower serum IGFBP3 levels and higher IGF1/IGFBP3 ratios compared to women.

Volunteers with sufficient data for this analysis (study participants) were younger, had less often diabetes mellitus, renal diseases, and hypertension, used less often antihypertensive medication, and had lower glucose levels than nonparticipants. Study participants revealed higher IGF1 and IGFBP3 levels and higher IGF1/IGFBP3 ratios than nonparticipants (Table 1).

We observed an inverse bivariate correlation between serum IGF1 levels and age in both women $(r=-0.447$; $P<0.001)$ and men $(r=-0.404 ; P<0.001)$. The inverse association between IGFBP 3 levels and age was weaker in women $(r=-0.247 ; P<0.001)$ than men $(r=-0.415 ; P<0.001)$. There was a stronger negative correlation between IGF1/IGFBP 3 ratio and age in women $(r=-0.379 ; P<0.001)$ than in men $(r=-0.153 ; \quad P<0.001)$. Bivariate comparisons between serum IGF1 levels and FMD showed a positive association in female $(r=0.075 ; P=0.041)$ and in male subjects $(r=0.203 ; P<0.001)$ respectively. Furthermore, we revealed no association between serum IGFBP 3 levels and FMD women $(r=0.027$; $P=0.466$ ), but a positive association in men $(r=0.130 ; P<0.001)$. Finally, there was a weaker positive correlation between IGF1/IGFBP3 ratio and FMD in women $(r=0.086 ; P=0.020)$ than in men $(r=0.151 ; P<0.001)$.

In multivariable logistic regression analyses, there was an age-adjusted OR of 1.28 (CI 1.08-1.53; $P=0.005)$ for decreased FMD in males with each decrement of IGF1 S.D. (S.D. $=51.9 \mathrm{ng} / \mathrm{ml}$; Table 2). Adjustment for further potential confounders including WC, hypertension, diabetes, liver and renal diseases, smoking status, and serum HDL- and LDL-cholesterol did not influence the major results substantially. 
Table 1 Selected characteristics of the study population and nonparticipants.

\begin{tabular}{|c|c|c|c|c|c|c|}
\hline & \multicolumn{6}{|c|}{ Study population } \\
\hline & $\begin{array}{l}\text { Women } \\
n=736\end{array}$ & $\begin{array}{c}\text { Men } \\
n=746\end{array}$ & $P^{\mathrm{a}}$ & $\begin{array}{l}\text { All participants } \\
n=1482\end{array}$ & $\begin{array}{c}\text { Nonparticipants } \\
n=1818\end{array}$ & $P^{\mathrm{a}}$ \\
\hline Age (years) & $51.1(12.8)$ & $53.1(14.0)$ & 0.009 & $52.1(13.5)$ & $56.4(16.4)$ & $<0.001$ \\
\hline Sex (male) & - & - & & 746 (50.3) & $843(46.4)$ & 0.023 \\
\hline Smoking status & & & $<0.001$ & & & 0.308 \\
\hline Never-smoker & $418(56.8)$ & $216(29.0)$ & & $634(42.8)$ & $744(41.1)$ & \\
\hline Ex-smoker & $150(20.4)$ & $337(45.2)$ & & $487(32.9)$ & $584(32.3)$ & \\
\hline Current smoker & $168(22.8)$ & $193(25.9)$ & & $361(24.4)$ & $483(26.7)$ & \\
\hline Body mass index $\left(\mathrm{kg} / \mathrm{m}^{2}\right)$ & $27.5(5.2)$ & $28.2(4.0)$ & $<0.001$ & $27.8(4.7)$ & $28.1(5.1)$ & 0.493 \\
\hline Waist circumference $(\mathrm{cm})$ & $86.6(12.9)$ & $98.1(11.5)$ & $<0.001$ & $92.4(13.5)$ & $92.9(14.4)$ & 0.443 \\
\hline Diabetes mellitus & $51(6.9)$ & $67(9.0)$ & 0.145 & $118(8.0)$ & $252(13.9)$ & $<0.001$ \\
\hline Liver diseases & $16(2.2)$ & $11(1.5)$ & 0.314 & $27(1.8)$ & $34(1.9)$ & 0.918 \\
\hline Renal diseases & $38(5.2)$ & 29 (3.9) & 0.237 & $67(4.5)$ & 205 (11.3) & $<0.001$ \\
\hline Systolic blood pressure $(\mathrm{mmHg})$ & $125.8(17.9)$ & $135.5(16.9)$ & $<0.001$ & $130.7(18.1)$ & $134.1(21.3)$ & $<0.001$ \\
\hline Diastolic blood pressure $(\mathrm{mmHg})$ & $79.7(9.5)$ & $83.7(10.4)$ & $<0.001$ & $81.7(10.1)$ & $81.1(11.0)$ & 0.007 \\
\hline Hypertension & $299(40.6)$ & $416(55.8)$ & $<0.001$ & $715(48.3)$ & $998(54.9)$ & $<0.001$ \\
\hline Use of antihypertensive medication & $244(33.2)$ & $269(36.1)$ & 0.240 & $513(34.6)$ & $853(46.9)$ & $<0.001$ \\
\hline HDL-cholesterol (mmol/l) & $1.35(0.43)$ & $1.02(0.33)$ & $<0.001$ & $1.18(0.42)$ & $1.17(0.43)$ & 0.578 \\
\hline LDL-cholesterol (mmol/l) & $3.50(1.06)$ & $3.55(0.98)$ & 0.172 & $3.52(1.02)$ & $3.53(1.00)$ & 0.832 \\
\hline Triglycerides $(\mathrm{mmol} / \mathrm{l})$ & $1.52(1.09)$ & $2.17(2.47)$ & $<0.001$ & $1.85(1.94)$ & $1.83(1.51)$ & 0.622 \\
\hline Glucose $(\mathrm{mmol} / \mathrm{l})$ & $5.22(1.11)$ & $5.48(1.40)$ & $<0.001$ & $5.35(1.27)$ & $5.66(1.84)$ & $<0.001$ \\
\hline Use of sex hormones & $127(17.3)$ & - & & $127(8.6)$ & $156(8.6)$ & 0.991 \\
\hline Number of pregnancies & & & & & & 0.051 \\
\hline 0 & $74(10.1)$ & - & & $820(55.3)$ & $929(51.1)$ & \\
\hline 1 & $155(21.1)$ & - & & $155(10.5)$ & $186(10.2)$ & \\
\hline 2 & $243(33.0)$ & - & & $243(16.4)$ & $322(17.7)$ & \\
\hline$\geq 3$ & $264(35.9)$ & - & & $264(17.8)$ & $381(21.0)$ & \\
\hline IGF1 levels (ng/ml) & $148.3(52.6)$ & $145.5(51.9)$ & 0.298 & $146.9(52.3)$ & $137.2(54.3)$ & $<0.001$ \\
\hline IGFBP3 levels (ng/ml) & $4225.0(867.2)$ & 3974.6 (953.4) & $<0.001$ & $4099.0(919.9)$ & 3916.6 (1048.3) & $<0.001$ \\
\hline IGF1/IGFBP3 ratio & $0.035(0.010)$ & $0.037(0.010)$ & $<0.001$ & $0.036(0.010)$ & $0.035(0.010)$ & 0.006 \\
\hline Baseline diameter of $A$. brachialis (mm) & $3.40(0.45)$ & $4.41(0.52)$ & $<0.001$ & $3.91(0.70)$ & - & - \\
\hline FMD (\%) & $5.75(4.28)$ & $4.31(3.23)$ & $<0.001$ & $5.03(3.86)$ & _ & _ \\
\hline
\end{tabular}

Data are given as number (percentage) or mean (s.D.). HDL, high-density lipoprotein; LDL, low-density lipoprotein; IGF1, insulin-like growth factor-1; IGFBP3, insulin-like growth factor-binding protein-3; FMD, flow-mediated dilation.

${ }^{a} \chi^{2}$-test (nominal data) or Mann-Whitney $U$ test (interval data).

In females, no significant association between serum IGF1 levels and FMD was identified after adjustment for age and further confounders (OR 0.88, CI 0.74-1.05; $P=0.147)$. In both men and women, no association between serum IGFBP3 levels and FMD was present. Only in males, there was a higher adjusted OR of 1.24 (CI 1.06-1.46; $P=0.009$ ) in the full model for decreased FMD with each decrement of IGF1/IGFBP3 ratio s.D. (s.D. $=0.0098$; Table 2). No findings changed substantially after usage of inverse probability weighting according to age, diabetes mellitus, and hypertension.

Additional analyses were performed after excluding subjects with antihypertensive medication. In the fully adjusted model in males, there was an OR of 1.40 (CI $1.12-1.75 ; P=0.003$ ) and an OR of 1.38 (CI 1.11$1.71 ; P=0.003)$ for decreased FMD with each decrement of serum IGF1 S.D. (S.D. $=48.1 \mathrm{ng} / \mathrm{ml}$ ) and IGF1/ IGFBP3 ratio s.D. (s.D. $=0.0093)$ respectively. The associations of IGF1 levels and IGF1/IGFBP3 ratio with FMD in women and serum IGFBP3 levels and FMD in women and men remained nonsignificant after these changes (Table 3). In further sensitivity analyses, height (of men and women) and current oral contraceptive use and number of pregnancies (in women) were used as additional confounding factors. These analyses did not change the main result of no association between IGF1 and IGFBP3 levels and IGF1/IGFBP3 ratio with FMD in women. In further analyses, multivariable models with an additional adjustment for serum TSH levels revealed apparently unchanged ORs for men of 1.26 (CI 1.06-1.50; $P=0.009$ ) and 1.40 (CI 1.12-1.75; $P=0.003$ ) and for women of 0.88 (CI $0.74-1.05 ; P=0.147$ ) and 0.95 (CI $0.77-1.16$; $P=0.601)$ for subjects including and without antihypertensive medication respectively.

\section{Discussion}

In the present population-based study, we detected an association between low serum IGF1 levels and decreased FMD in men after adjustment for age. Adjustment for further confounding cardiovascular risk factors including abdominal obesity, diabetes mellitus, hypertension, liver and renal diseases, smoking status, as well as HDL- and LDL-cholesterol levels did not have significant impact on this major finding. Various antihypertensive medications such as 
Table 2 The relationship between serum IGF1/IGFBP3 levels and decreased FMD in women and men.

\begin{tabular}{|c|c|c|c|c|}
\hline \multirow[b]{3}{*}{ Models } & \multicolumn{4}{|c|}{ Decreased FMD ${ }^{\mathrm{a}}$} \\
\hline & \multicolumn{2}{|c|}{ Women } & \multicolumn{2}{|c|}{ Men } \\
\hline & OR $(95 \% \mathrm{Cl})$ & $P^{\mathrm{b}}$ & OR $(95 \% \mathrm{Cl})$ & $P^{\mathrm{b}}$ \\
\hline \multicolumn{5}{|c|}{ IGF1 (s.D. decrement) } \\
\hline Model 1 & $0.89(0.75-1.06)$ & 0.184 & $1.28(1.08-1.53)$ & 0.005 \\
\hline Model 2 & $0.88(0.74-1.05)$ & 0.147 & $1.27(1.07-1.51)$ & 0.008 \\
\hline \multicolumn{5}{|c|}{ IGFBP3 (S.D. decrement) } \\
\hline Model 1 & $1.03(0.88-1.20)$ & 0.751 & $1.05(0.89-1.24)$ & 0.527 \\
\hline Model 2 & $1.01(0.86-1.19)$ & 0.912 & $1.05(0.89-1.25)$ & 0.550 \\
\hline \multicolumn{5}{|c|}{ IGF1/IGFBP3 ratio (s.D. decrement) } \\
\hline Model 1 & $0.87(0.74-1.03)$ & 0.108 & $1.24(1.06-1.45)$ & 0.007 \\
\hline Model 2 & $0.87(0.74-1.03)$ & 0.103 & $1.24(1.06-1.46)$ & 0.009 \\
\hline
\end{tabular}

Models: 1 (adjusted for age); 2 (+ adjusted for waist circumference, hypertension, diabetes mellitus, liver and renal diseases, smoking status, and HDL- and LDL-cholesterol). IGF1, insulin-like growth factor-1; IGFBP3, insulin-like growth factor-binding protein-3; FMD, flow-mediated dilation; OR, odds ratio; $\mathrm{Cl}$, confidence interval.

a $<$ Median $(<5.17 \%$ for women; $<3.96 \%$ for men)

bogistic regression.

$\beta$-blockers, ACE inhibitors, or angiotensin II receptor blockers modulate endothelial function (25). Exclusion of volunteers with current use of antihypertensive medication from the analysis revealed no significant impact on the association of IGF1 and FMD in our study. Since circulating IGF1 is predominantly bound by IGFBP3 (8), we performed separate analyses to detect a potential differing association between IGF1/IGFBP3 ratio and FMD. All of these findings were similar when the IGF1/IGFBP3 ratio was analyzed instead of IGF1 levels. This fact indicates the biological relevance of the association between IGF1 levels and FMD in men.

An association between low serum IGF1 levels and impaired endothelium-mediated vasodilation has been described previously in a population of 100 untreated, hypertensive subjects (18). Since the authors did not present data analysis separately for men $(n=65)$ and women $(n=35)$, it cannot be excluded that the observed association of IGF1 levels and acetylcholine-induced forearm blood flow in their whole population was due to the preponderance of male subjects. Other studies focussing on the relationship of serum IGF1 levels and endothelial function were even smaller and primarily confined to patients with disturbed GH secretion, such as acromegaly or GH deficiency (15-17). In patients with low $(15,16)$ and high (17) preinterventional serum IGF1 levels, normalization of IGF1 levels led to an improvement of previously reduced FMD. In these studies, gender-specific analysis was either not discussed or considered impossible due to the small number of patients (15). Our study comprised 1482 subjects with a broad age range (25-85 years) and IGF 1 levels largely within the reference range, which points toward a relevant impact of IGF1 on the cardiovascular system in male subjects under physiological circumstances.

Table 3 The relationship between serum IGF1/IGFBP3 levels and decreased FMD in women and men without antihypertensive medication.

\begin{tabular}{|c|c|c|c|c|}
\hline \multirow[b]{3}{*}{ Models } & \multicolumn{4}{|c|}{ Decreased FMD } \\
\hline & \multicolumn{2}{|c|}{ Women } & \multicolumn{2}{|c|}{ Men } \\
\hline & OR $(95 \% \mathrm{Cl})$ & $P^{\mathrm{b}}$ & OR $(95 \% \mathrm{Cl})$ & $P^{\mathrm{b}}$ \\
\hline \multicolumn{5}{|c|}{ IGF1 (s.D. decrement) } \\
\hline Model 1 & $0.96(0.78-1.18)$ & 0.695 & $1.35(1.09-1.68)$ & 0.005 \\
\hline Model 2 & $0.95(0.77-1.16)$ & 0.595 & $1.40(1.12-1.75)$ & 0.003 \\
\hline \multicolumn{5}{|c|}{ IGFBP3 (s.D. decrement) } \\
\hline Model 1 & $1.04(0.86-1.26)$ & 0.677 & $1.09(0.89-1.32)$ & 0.410 \\
\hline Model 2 & $0.99(0.81-1.21)$ & 0.926 & $1.09(0.88-1.34)$ & 0.450 \\
\hline \multicolumn{5}{|c|}{ IGF1/IGFBP3 ratio (s.D. decrement) } \\
\hline Model 1 & $0.93(0.76-1.13)$ & 0.440 & $1.29(1.06-1.58)$ & 0.011 \\
\hline Model 2 & $0.94(0.76-1.15)$ & 0.542 & $1.38(1.11-1.71)$ & 0.003 \\
\hline
\end{tabular}


The association between IGF1 and decreased FMD as a marker of preclinical atherosclerosis in men might represent a possible link to cardiovascular morbidity and mortality. Indeed, we have recently demonstrated that men with low IGF1 levels had an almost twofold higher risk of cardiovascular disease mortality compared to men with normal IGF1 levels (26). However, Andreassen et al. (27) recently described an increased mortality and risk of heart failure in elderly subjects with high IGF1 levels.

In contrast to men, serum IGF1 levels did not reveal any relevant influence on FMD in women in our analysis. In concordance with this finding, no association between serum IGF1 levels and mortality (26) and risk of myocardial infarction (28) was found in women. Few studies have addressed possible sex differences in cardiovascular risk factors in relation to the GH/IGF system. Sexual dimorphism exists in GH secretion: women in their fertile age have higher serum GH levels and lower serum IGF1 levels than men (29). Moreover in patients with GH deficiency receiving GH replacement therapy, sex-specific effects have been described (30). Men require lower GH doses than women (31), and have apparently greater benefits from the substitution with regard to improvement in body composition, lipid profile, and bone mass (32). While these findings are in good agreement with the sex-specific associations found in our study, the mechanisms underlying this sex specificity remain to be investigated.

Our study has several potential limitations and strengths that should be considered. Limitations arise from the cross-sectional study design, ruling out any interpretation on causal inferences in the association of IGF 1 and FMD. Unfortunately, GH and insulin levels are not available for the SHIP-1 population. Thus, estimates of insulin resistance status are difficult to obtain. Generalization of our findings might be limited due to selection bias because our study population (with both complete examinations of FMD of sufficient quality and available IGF1 and IGFBP3 datasets) differed from the whole SHIP-1 population in some potential confounders. However, inverse probability weighting according to age, diabetes mellitus, and hypertension confirmed that our findings were not biased by the differences among these variables between study population and nonparticipants.

Major strengths are the population-based design, the accurate FMD measurement under strict quality management by standardized protocol and certified staff (23), the comprehensive and detailed assessment of metabolic and cardiovascular confounding factors $(19,20)$, and the size of the study population. The method of forearm ischemia induction of FMD precludes the potential contribution of ischemia of the brachial artery itself - in contrast to upper arm ischemia-induced FMD, which is known to induce more vasodilation $(33,34)$.
In conclusion, low serum IGF1 levels are associated with impaired endothelial function in males, which might represent a possible link to increased cardiovascular morbidity and mortality. In women, serum IGF1 is not associated with endothelial function.

\section{Declaration of interest}

The authors declare that there is no conflict of interest that could be perceived as prejudicing the impartiality of the research reported.

\section{Funding}

This work was funded by grants from the German Federal Ministry of Education and Research (BMBF, Grants 01ZZ0403, 01ZZ0103, and 01GI0883), the Ministry for Education, Research, and Cultural Affairs, as well as the Ministry of Social Affairs of the Federal State of Mecklenburg-West Pomerania. Pfizer provided partial grant support for the determination of plasma samples and data analysis.

\section{Acknowledgements}

This work is part of the Community Medicine Research net (CMR; http://www.medizin.uni-greifswald.de/icm) of the University of Greifswald. The CMR encompasses several research projects, which share population-based data from the Study of Health in Pomerania (SHIP; http://ship.community-medicine.de). The contributions to data collection made by field workers, study physicians, ultrasound technicians, interviewers, and computer assistants are gratefully acknowledged.

\section{References}

1 Sara VR \& Hall K. Insulin-like growth factors and their binding proteins. Physiological Reviews 199070 591-614.

2 Rinderknecht E \& Humbel RE. The amino acid sequence of human insulin-like growth factor I and its structural homology with proinsulin. Journal of Biological Chemistry 1978253 2769-2776.

3 Mathews LS, Norstedt G \& Palmiter RD. Regulation of insulin-like growth factor I gene expression by growth hormone. PNAS 1986 83 9343-9347. (doi:10.1073/pnas.83.24.9343)

4 Sowers JR. Insulin and insulin-like growth factor in normal and pathological cardiovascular physiology. Hypertension 199729 691-699.

5 Chisalita SI \& Arnqvist HJ. Insulin-like growth factor I receptors are more abundant than insulin receptors in human micro- and macrovascular endothelial cells. American Journal of Physiology. Endocrinology and Metabolism 2004286 E896-E901. (doi:10. 1152/ajpendo.00327.2003)

6 Tsukahara H, Gordienko DV, Tonshoff B, Gelato MC \& Goligorsky MS. Direct demonstration of insulin-like growth factor-I-induced nitric oxide production by endothelial cells. Kidney International 199445 598-604. (doi:10.1038/ki.1994.78)

7 Walsh MF, Barazi M, Pete G, Muniyappa R, Dunbar JC \& Sowers JR. Insulin-like growth factor I diminishes in vivo and in vitro vascular contractility: role of vascular nitric oxide. Endocrinology 1996137 1798-1803. (doi:10.1210/en.137.5.1798)

8 Juul A. Serum levels of insulin-like growth factor I and its binding proteins in health and disease. Growth Hormone and IGF Research 200313 113-170. (doi:10.1016/S1096-6374(03)00038-8)

9 Deanfield JE, Halcox JP \& Rabelink TJ. Endothelial function and dysfunction: testing and clinical relevance. Circulation $2007 \mathbf{1 1 5}$ 1285-1295. (doi:10.1161/CIRCULATIONAHA.106.652859)

10 Martin RM, Gunnell D, Whitley E, Nicolaides A, Griffin M, Georgiou N, Davey Smith G, Ebrahim S \& Holly JM. Associations of insulin-like growth factor (IGF)-I, IGFII, IGF binding protein (IGFBP)-2 and IGFBP-3 with ultrasound measures of 
atherosclerosis and plaque stability in an older adult population. Journal of Clinical Endocrinology and Metabolism 200893 1331-1338. (doi:10.1210/jc.2007-2295)

11 Juul A, Scheike T, Davidsen M, Gyllenborg J \& Jorgensen T. Low serum insulin-like growth factor I is associated with increased risk of ischemic heart disease: a population-based case-control study. Circulation 2002106 939-944. (doi:10.1161/01.CIR. 0000027563.44593.CC)

12 Johnsen SP, Hundborg HH, Sorensen HT, Orskov H, Tjonneland A, Overvad K \& Jorgensen JO. Insulin-like growth factor (IGF) I, -II, and IGF binding protein-3 and risk of ischemic stroke. Journal of Clinical Endocrinology and Metabolism 200590 5937-5941. (doi:10.1210/jc.2004-2088)

13 Kaplan RC, McGinn AP, Pollak MN, Kuller LH, Strickler HD, Rohan TE, Cappola AR, Xue X \& Psaty BM. Association of total insulin-like growth factor-I, insulin-like growth factor binding protein-1 (IGFBP-1), and IGFBP-3 levels with incident coronary events and ischemic stroke. Journal of Clinical Endocrinology and Metabolism 200792 1319-1325. (doi:10.1210/jc.2006-1631)

14 Laughlin GA, Barrett-Connor E, Criqui MH \& Kritz-Silverstein D. The prospective association of serum insulin-like growth factor I (IGF-I) and IGF-binding protein-1 levels with all cause and cardiovascular disease mortality in older adults: the Rancho Bernardo Study. Journal of Clinical Endocrinology and Metabolism 200489 114-120. (doi:10.1210/jc.2003-030967)

15 Abdu TA, Elhadd TA, Buch H, Barton D, Neary R \& Clayton RN. Recombinant GH replacement in hypopituitary adults improves endothelial cell function and reduces calculated absolute and relative coronary risk. Clinical Endocrinology 200461 387-393. (doi:10.1111/j.1365-2265.2004.02109.x)

16 van der Klaauw AA, Pereira AM, Rabelink TJ, Corssmit EP, Zonneveld AJ, Pijl H, de Boer HC, Smit JW, Romijn JA \& de Koning EJ. Recombinant human GH replacement increases CD34+ cells and improves endothelial function in adults with GH deficiency. European Journal of Endocrinology 2008159 105-111. (doi:10.1530/EJE-08-0179)

17 Sakai H, Tsuchiya K, Nakayama C, Iwashima F, Izumiyama H, Doi M, Yoshimoto T, Tsujino $M$, Yamada $S$ \& Hirata $Y$. Improvement of endothelial dysfunction in acromegaly after transsphenoidal surgery. Endocrine Journal 200855 853-859. (doi:10.1507/endocrj.K07E-125)

18 Perticone F, Sciacqua A, Perticone M, Laino I, Miceli S, Care I, Galiano Leone G, Andreozzi F, Maio R \& Sesti G. Low-plasma insulin-like growth factor-I levels are associated with impaired endothelium-dependent vasodilatation in a cohort of untreated, hypertensive Caucasian subjects. Journal of Clinical Endocrinology and Metabolism 200893 2806-2810. (doi:10.1210/jc.20080646)

19 Volzke H, Alte D, Schmidt CO, Radke D, Lorbeer R, Friedrich N, Aumann N, Lau K, Piontek M, Born G, Havemann C, Ittermann T, Schipf S, Haring R, Baumeister SE, Wallaschofski H, Nauck M, Frick S, Arnold A, Junger M, Mayerle J, Kraft M, Lerch MM, Dorr M, Reffelmann T, Empen K, Felix SB, Obst A, Koch B, Glaser S, Ewert R, Fietze I, Penzel T, Doren M, Rathmann W, Haerting J, Hannemann M, Ropcke J, Schminke U, Jurgens C, Tost F, Rettig R, Kors JA, Ungerer S, Hegenscheid K, Kuhn JP, Kuhn J, Hosten N, Puls R, Henke J, Gloger O, Teumer A, Homuth G, Volker U, Schwahn C, Holtfreter B, Polzer I, Kohlmann T, Grabe HJ, Rosskopf D, Kroemer HK, Kocher T, Biffar R, John U \& Hoffmann W. Cohort profile: the Study of Health in Pomerania. International Journal of Epidemiology 2010 In Press. (doi:10.1093/ije/dyp394)

20 John U, Greiner B, Hensel E, Ludemann J, Piek M, Sauer S, Adam C, Born G, Alte D, Greiser E, Haertel U, Hense HW, Haerting J, Willich S \& Kessler C. Study of Health in Pomerania (SHIP): a health examination survey in an east German region: objectives and design. Sozial- und Präventivmedizin 200146 186-194. (doi:10.1007/BF01324255)
21 Cockcroft DW \& Gault MH. Prediction of creatinine clearance from serum creatinine. Nephron 197616 31-41. (doi:10.1159/ 000180580)

22 Krebs A, Wallaschofski H, Spilcke-Liss E, Kohlmann T, Brabant G, Volzke H \& Nauck M. Five commercially available insulin-like growth factor I (IGF-I) assays in comparison to the former Nichols Advantage IGF-I in a growth hormone treated population. Clinical Chemistry and Laboratory Medicine 200846 1776-1783. (doi:10. 1515/CCLM.2008.349)

23 Volzke H, Robinson DM, Spielhagen T, Nauck M, Obst A, Ewert R, Wolff B, Wallaschofski H, Felix SB \& Dorr M. Are serum thyrotropin levels within the reference range associated with endothelial function? European Heart Journal 200930 217-224. (doi:10.1093/eurheartj/ehn508)

24 Little RJ \& Vartivarian S. On weighting the rates in non-response weights. Statistics in Medicine 200322 1589-1599. (doi:10. $1002 / \operatorname{sim} .1513$ )

25 Landmesser U \& Drexler H. Endothelial function and hypertension. Current Opinion in Cardiology 200722 316-320. (doi:10.1097/ HCO.0b013e3281ca710d)

26 Friedrich N, Haring R, Nauck M, Ludemann J, Rosskopf D, SpilckeLiss E, Felix SB, Dorr M, Brabant G, Volzke H \& Wallaschofski H. Mortality and serum insulin-like growth factor I and insulin-like growth factor binding protein 3 concentrations. Journal of Clinical Endocrinology and Metabolism 200994 1732-1739. (doi:10. 1210/jc.2008-2138)

27 Andreassen M, Raymond I, Kistorp C, Hildebrandt P, Faber J \& Kristensen LO. IGF1 as predictor of all cause mortality and cardiovascular disease in an elderly population. European Journal of Endocrinology 2009160 25-31. (doi:10.1530/EJE-08-0452)

28 Page JH, Ma J, Pollak M, Manson JE \& Hankinson SE. Plasma insulinlike growth factor 1 and binding-protein 3 and risk of myocardial infarction in women: a prospective study. Clinical Chemistry 200854 1682-1688. (doi:10.1373/clinchem.2008. 105825)

29 Gatford KL, Egan AR, Clarke IJ \& Owens PC. Sexual dimorphism of the somatotrophic axis. Journal of Endocrinology 1998157 373-389. (doi:10.1677/joe.0.1570373)

30 Span JP, Pieters GF, Sweep FG, Hermus AR \& Smals AG. Gender differences in rhGH-induced changes in body composition in GH-deficient adults. Journal of Clinical Endocrinology and Metabolism 200186 4161-4165. (doi:10.1210/jc.86.9.4161)

31 Burman P, Johansson AG, Siegbahn A, Vessby B \& Karlsson FA. Growth hormone (GH)-deficient men are more responsive to $\mathrm{GH}$ replacement therapy than women. Journal of Clinical Endocrinology and Metabolism 199782 550-555. (doi:10.1210/jc.82.2.550)

32 Johansson AG. Gender difference in growth hormone response in adults. Journal of Endocrinological Investigation 199922 58-60.

33 Corretti MC, Anderson TJ, Benjamin EJ, Celermajer D, Charbonneau F, Creager MA, Deanfield J, Drexler H, GerhardHerman M, Herrington D, Vallance P, Vita J \& Vogel R. Guidelines for the ultrasound assessment of endothelial-dependent flowmediated vasodilation of the brachial artery: a report of the International Brachial Artery Reactivity Task Force. Journal of the American College of Cardiology 200239 257-265. (doi:10.1016/ S0735-1097(01)01746-6)

34 Guthikonda S, Sinkey CA \& Haynes WG. What is the most appropriate methodology for detection of conduit artery endothelial dysfunction? Arteriosclerosis, Thrombosis, and Vascular Biology 200727 1172-1176. (doi:10.1161/ATVBAHA.106. 131011)

Received 18 July 2010

Accepted 23 July 2010 